\title{
8 Vienna's urban green space planning
}

\section{Great stability amid global change}

\section{Anna-Katharina Brenner, Elisabetta Mocca, and Michael Friesenecker}

\section{Introduction}

Urban green space (hereafter UGS) planning has been concerned with how to introduce and institutionalise new governing policies that encourage specific qualities of green spaces, considering both social and environmental dimensions. UGS is a comprehensive term, indicating areas of vegetation in an urban landscape, and has been associated with several benefits in terms of residents' health and wellbeing (e.g. Maas et al., 2006). Historically, UGS has been employed as a planning tool to approach various social problems, whilst its value in adapting to the negative impacts of the climate crisis has only recently gained importance (Loughran, 2020).

From a theoretical standpoint, environmental justice (EJ) research emphasises how these positive effects (as well as environmental hazards) associated with UGS are often spatially unequally distributed in cities (Walker, 2012). Whilst a growing number of studies on European cities have analysed the (uneven) distribution and availability of UGS per inhabitant (see Kabisch et al., 2016), too little is known about how urban conditions and their transformation over time have put pressure on the availability of UGS to diverse social groups (Rutt and Gulsrud, 2016). From a political perspective, it has been noted that social-democratic welfare states appear to better integrate social and environmental policies than liberal market economies (Dryzek, 2003), as they make 'conscious and coordinated' efforts to mutually reinforce ecologic and economic values (Gough et al., 2008, pp. 334-335). Yet, according to Rutt and Gulsrud (2016, p. 124), 'if and how urban managers take up issues of diversity and inclusion in their daily and strategic UGS management' remains an under-researched topic. 
Against this background, Vienna constitutes an interesting case study, as it has maintained its high share of UGS (almost 50\% of the city area) over the past 30 years. Compared to other European cities, Vienna has been a pioneer in UGS planning (Anguelovski et al., 2018). However, over the last three decades, the city has experienced a set of profound transformations, including population growth, sociodemographic shifts, increasing inequalities (Riederer et al., 2019), environmental changes (in particular shifting weather events), and new governing arrangements as a result of Austria's accession to the European Union. Therefore, we aim to investigate how these transformations have shaped Vienna's UGS policies, its institutional settings, and formal and informal rules (Sorensen, 2017), as well as their outcomes in terms of just provision of UGS.

EJ, operationalised through the concepts of distribution and recognition, will be adopted to analyse two key policy dimensions. First, we were interested in the institutional setting and ideals/values of Vienna's strategic UGS policy and how it has changed over time. In particular, this chapter will examine how population growth and changing multi-level arrangements in the last 30 years have modified UGSrelated planning in Vienna. That aim implies a focus on how different needs have come to be recognised in strategic planning documents. We performed an extensive literature review and document analysis concerning UGS in Vienna, covering the 30-year reference period to investigate the evolution of Vienna's UGS policy. Expert interviews supplemented the document analysis. Second, we examine how UGS policy has shaped the distribution and availability of green spaces. In so doing, we used availability as a simple indicator (Kronenberg et al., 2020) to analyse whether residents have access to UGS in close proximity to where they live. The amount of UGS per inhabitant within a $250 \mathrm{~m}$ radius was in focus, and we analyse changes in availability between 2001 and 2018 .

\section{Vienna's UGS governance: a complex set of public actors}

The institutional setting of UGS governance in Vienna is shaped by a complex network of public actors across different governing levels. At the municipal level, three main actors shape UGS governance: The Municipal Department of Urban Planning (MA18), the Municipal Department for Environmental Protection (MA22), and the Municipal Department for District Planning and Land Use (MA21). The former is responsible for devising strategic, non-binding urban development plans (Stadtentwicklungsplan, hereafter STEP), including (spatial) UGS concepts after being approved by the city council, which shape ideals 
and values. The MA22, established during the 1980s, is responsible for the implementation of regional, federal and the EU legal frameworks in the field of nature protection. The MA21, in charge of the land zoning process, implements the strategic non-binding urban development plans, including the zoning of nature protected areas, which is regulated by the Viennese Building Code (BO). Thus, the latter is an important instrument in shaping the distribution of UGS across the city. Other relevant municipal departments responsible for administrating UGS are the Municipal Department for Parks and Gardens (MA42) and the Municipal Department of the Forestry Office and Urban Agriculture (MA49). The budget for the Planning Department is limited. But the latter two bodies account for a considerable proportion of the City expenditures. Between 1999 and 2019, they spent 1\% of the City's budget annually, whilst the absolute expenditures increased to about 100 million Euros per annum (MA5, 2020).

Changes in the City Statute in 1988 endowed the 23 districts of Vienna with greater responsibilities, whilst the budget was transferred on a task-specific basis. Within this decentralised system, districts are responsible for planning, constructing, renewing and maintaining UGS in cooperation with responsible municipal departments. Investments in UGS differ quite substantially between the districts (from 5\% to $18 \%$ in 2019), depending on the districts' amount of green space that needs to be maintained as well as activities to extend UGS. However, these 'local' budgets mainly cover maintenance, leaving only a small portion to expand UGS. Thus, districts normally apply for additional financial resources from central city resources for such activities.

UGS managed by the districts mainly include small-scale greening initiatives, whereas large-scale green areas (such as some parks and cemeteries) fall under the responsibility of the City. Furthermore, influence from the federal level on Vienna's UGS governance is limited to the design and maintenance of seven federal gardens (such as the famous 'Schönbrunn Gardens'). A legacy of the Habsburg Era, these gardens contribute to shaping the image of the city and constitute important tourism attractions. Nevertheless, the federal level has little to no influence on UGS planning, in contrast to the increasing influence of the EU, which will be discussed in more detail in the next section.

\section{Vienna's changing UGS policy: between urban development and urban renewal}

In policy discourses, UGS is historically tied to (industrial) urbanisation and population growth. Hence, some European cities have focused on the maintenance and legal protection of their green belts 
to attenuate urban sprawl, to provide urban dwellers with access to forestry, agriculture, and recreational areas, and to secure ecological functions, such as the provision of fresh air (Bishop et al., 2020). The history of modern UGS planning spans over a century in Vienna, and its development has been shaped by a range of institutional actors across multiple governing levels, as illustrated in Figure 8.1. In 1905, given the rapid expansion of the urban boundaries, the council decided to legally protect the Viennese forest and meadow belt, mostly covering the western outskirts of the city (Breiling and Ruland, 2008, p. 170) to ensure the provision of clean air to citizens and protect Vienna's wilderness. Although initiated in a period characterised by $\mathrm{Mu}$ nicipal Populism under Mayor Karl Lueger (Suitner, 2020, p. 10), the institutionalisation of the protection of the green belt represents a first milestone in the city's history. The social and health-oriented UGS approach of the city government was crucially shaped by the protection of the Viennese green belt, during the Red Vienna period, after the Second World War, and has an impact even today.

Between the 1960s and 1980s, when many residents moved from the dense inner-city districts to housing estates in the peripheral districts, the Social-Democratic City Government implemented large-scale projects at the periphery (Rode and Schwab, 2017). Probably the most iconic project of this era is the Danube Island (Donauinsel). On the one hand, this work sought to control flooding; on the other hand, it provided the city with wide green recreational areas.

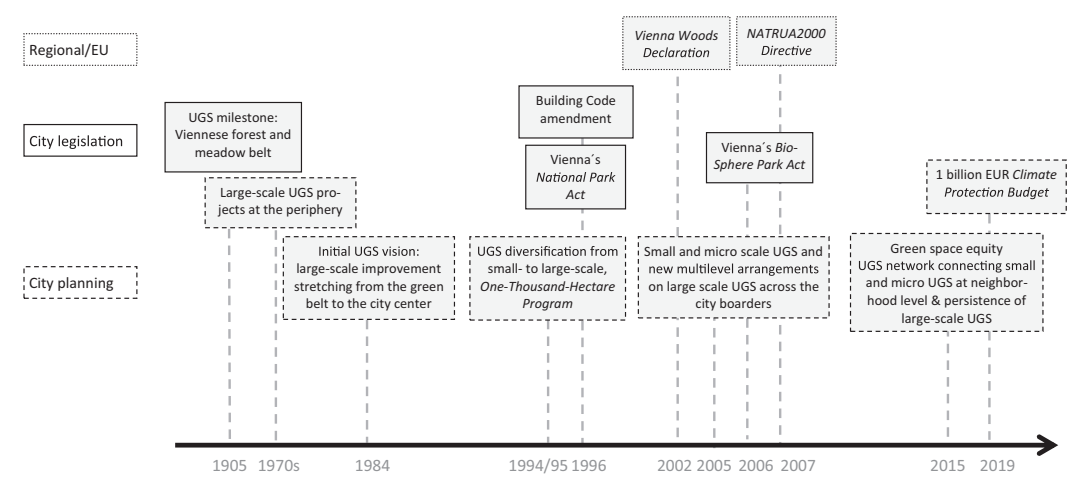

Figure 8.1 Timeline of central UGS policies at different governing levels between 1905 and 2019.

Source: Authors' own. 


\section{Recent developments in large-scale UGS protection}

Vienna's first urban development plan, approved by the city council in 1984, emphasised the necessity of improving the population's living conditions through welfare-oriented economic development and by protecting, maintaining and developing healthy and liveable environments to counter the city's population decline, driven by suburbanisation (MA18, 1984, p. 11). To this end, the plan proposed a shift from the dominant focus on the urban development of previous decades towards urban renewal, de-densification and expansion of UGS in densely populated inner-city areas. Children, young people, and the elderly were considered to be particularly exposed by the existing urban conditions; thus, UGS was to be designed considering their needs. Nevertheless, the strategic planning vision focused on large-scale improvements, such as green corridors, green patches, and green islands to connect inner-city areas with the parts of the green belt (MA18, 1984, p. 76). This strategy makes Vienna a pioneering city in green space planning in the European context. Other cities, such as Stuttgart, Sheffield or Birmingham, adopted similar strategies in the 1990s, and in some cases (e.g. Leeds, Barcelona), even in the 2000s (Anguelovski et al., 2018).

Throughout the early 1990s, UGS policy had to come to terms with population growth. Furthermore, as a result of Austria's accession to the EU in 1995, the city council expected Vienna to be exposed to competitive conditions within the single market. Yet, EU membership was seen as a chance to establish Vienna as a regional economic centre (Mocca et al., 2020). In effect, throughout the 1990s, the dominant narrative was characterised by a positive attitude towards moderate urban expansion and growth. That attitude framed the protection, maintenance, and expansion of UGS vis-á-vis pressures from urban development and new housing construction. Similar to other UGS leading cities of today, such as Copenhagen, the management of UGS in urban development areas acquired greater importance for the administration in this period (Anguelovski et al., 2018). The 1994 plan defined quantitative criteria that should guarantee $3-5 \mathrm{~m}^{2}$ of UGS per inhabitant as a non-binding guideline. Nevertheless, the administration refrained from applying these criteria to inner-city areas because of the structural preconditions but a commitment to small-scale improvements was set up (MA18, 1994). Recognising the different needs of certain social groups in the UGS planning process, women's needs, especially working mothers, were accounted for as part of the gender mainstreaming trend sweeping through Vienna's agencies. 
Against the changing demographic and economic context mentioned above, the city government primarily sought to secure its largescale UGS. Most importantly, the council passed a resolution, the so-called One-Thousand-Hectare Program, to expand the green belt in 1995. This resolution mainly aimed at the legal protection of the existing green belt through new zoning schemes and extending the belt in the previously unprotected north-eastern parts of Vienna by buying urban land. In achieving the former, the building code was amended in 1996, and a new legal act - the so-called Vienna's National Park Actwas implemented to adapt the legal framework of nature protection. Changes to the building code comprised new zoning categories that specifically designated legally protected areas in the green belt, including agricultural land and selected parks. These zoning categories are Vienna's highest UGS protection measures, as they are equivalent to a building ban, and it is hard to rezone these areas for other purposes. At that time, not many other European cities strived for such a large-scale and sustainable preservation of UGS. Those who did, such as Marseille, had similar financing problems in the face of population growth (Anguelovski et al., 2018). By 2003, 95\% of the planned areas were put under these kinds of zoning categories, whereby only a small share of UGS located in the green belt was bought by the City (Rechnungshof Österreich, 2005). Population growth was under-estimated by the council and increasing housing demand led to a worrying scarcity of building land and soaring land prices - factors that made the acquisition of UGS by the city difficult (Rechnungshof Österreich, 2005).

\section{The impact of changing multi-level arrangements}

Influenced by the EU's 'calls for sustainable, yet competitive territorial development', urban planning shifted in the early 2000s towards a 'managerial' governance style, characterised by the involvement of non-public actors (Suitner, 2020, p. 15). Additionally, regional economic policy became as important as the social and environmental policies of the previous decades, which aimed at ensuring equal opportunities and an adequate quality of life for all residents. The following quote from the 2005 Urban Development Plan (STEP05, see Figure 8.1) exemplifies this shift in urban development - which can also be observed in other European UGS pioneer cities such as Copenhagen and Munich (Anguelovski et al., 2018):

In a development geared towards sustainability, the maintenance and further development of the landscapes and the green and 
open spaces represent an integral component of economic locational development and is a basis of the long-term preservation of the quality of life.

(MA18, 2005, p. 55)

Given the growth of an increasingly demographically diversified population resulting from migration to Vienna following the Fall of the Iron Curtain (1989), the Yugoslav Wars (1991-2001), and the eastward enlargement of the EU (2004), UGS planning sought to acknowledge different needs, signalling an increasingly spatially differentiated approach to UGS development. Simultaneously, the 'steep population growth' prompted the administration to recognise the uneven distribution of green spaces (MA18, 2005, p. 19). The plan acknowledged that low-income neighbourhoods were characterised by inadequate housing conditions and a lack of large green spaces. That led to a change in the City's spatial vision: in addition to large-scale development, small and micro-scale approaches began to be seen as crucial to meet the needs of different ethnic groups and urban dwellers with disabilities. This vision foresaw the expansion and renewal of existing green spaces and further development of green spaces on inner-city brownfield sites. Moreover, the plan also introduced micro-scale greening of public spaces, such as squares, streets and pedestrian zones.

Although small-scale and micro-scale UGS are gaining importance in strategic planning, the new multi-level arrangement via Austria's accession to the EU increased the protection of large UGS across the city boundaries. New regulations such as the NATURA2000 Directive (the Vienna Woods Declaration) further secured and protected additional parts of the Vienna Woods including a UNESCO biosphere park in 2006 (Vienna's Biosphere Park Act) and the spring water protection forests in Lower Austria and Styria. These UGS provide the city with important ecological functions, such as high-quality water supply, fresh air and recreational areas for urban dwellers.

\section{Towards small-and micro-scale improvements}

Whilst the 2005 urban development plan marked a shift towards revitalising UGS development in densely built-up areas, the SPÖ-Greens coalition government formed in 2010 further intensified this shift. The uneven distribution of UGS was problematic for the administration, which had to deal with the effects of steep population growth, demographic challenges, and the impact of climate change. The city council began to recognise that the provision of large-scale UGS alone was 
insufficient to address urban environmental problems stemming from climate change, such as hotter and drier temperatures recognisable by the soaring increase in heat days (ZAMG-Klimaabteilung, 2019). In particular, elderly and deprived urban dwellers living in dense, innercity areas affected by urban heat island effects have been increasingly recognised as vulnerable groups by the administration.

Inspired by UGS planning strategies of other European cities, such as Stockholm and Amsterdam, in 2015 the city council approved Vienna's Thematic Concept for Green and Open Spaces, which integrates for the first time in Vienna's history - the general principle of Green Space Equity. As an urban planning principle, green space equity implies that 'all citizens have the same right to the high-quality provision of green and open space' (MA18, 2015, p. 15). Green space equity is operationalised as the availability of $3.5 \mathrm{~m}^{2}$ of UGS per inhabitant within a distance of $250 \mathrm{~m}$ for all urban dwellers (MA18, 2015, p. 84). That includes the creation of lively and green streetscapes and pedestrian zones (e.g. Mariahilferstraße or Kärtnerstraße), of green elements in the streets, including adjacent green spaces (e.g. Ringstraße, Grätzl Oase), of façade greenery and the greening of brownfields (e.g. Gaudenzdorfer Gürtel).

The concept marked a clear discursive shift towards improving green spaces at the immediate neighbourhood scale and pre-structures the application of different green space types according to urban forms and changing needs of urban dwellers. Here, the expected demographic changes, where the proportion of elderly and migrant populations were predicted to increase, led to shifts in requirements for the design and quality of UGS. Access to larger UGS recreational areas should be granted for all urban dwellers by public transport. Thereby, the traditional city government's focus on securing large-scale UGS and prioritising the provision of parks and vast recreational areas at the city fringes persisted. The new aspect in this was the development of a Green Space Network Plan, creating and connecting distributed micro- and small-scale UGS. That included greening measures targeting streets and pedestrian zones, reclaiming public space from motorised-individual transport. Thus, opening a new discussion concerning the fair distribution of public space linked to the increasingly noticeable effects of climate change.

The implementation of small and micro-spaces, however, has proved to be difficult in the current multi-level setting. For example, districts have the authority to enforce or delay greening strategies as a result of the additional UGS planning competencies they were granted in 1998. The reclamation of parking spaces to make room for urban 
green remains conflictual due to opposing interests of residents, district representatives, urban planners and administration, city politicians and social partners. However, this conflictual dynamic is slowly changing in light of hotter and drier temperatures. By enforcing local small-scale greening measures, urban dwellers and district representatives are starting to cooperate, also in districts that are relatively car-dominated.

Additionally, as district budgets mainly cater for the maintenance of existing UGS, substantial challenges have arisen in the funding of additional UGS. The cost of planting a tree, for instance, can be high, varying between 300 and 3,000 Euros - costing more in less favourable conditions, such as densely built urban areas. Therefore, districts need a high commitment to UGS implementation and depend on additional financial aid. In this respect, it is important to note the 1-billion Euro climate protection budget approved by the city government in 2019, of which 64 million Euros were devoted to expanding and improving parks and green spaces, and a 2.3 million Euro funding package for cooling efforts to adapt to urban heat islands on a local scale (OekoBusinessWien, 2019). An additional source of funding for districts is EU-funded local development programs, by which some local UGS projects have been implemented (see City of Vienna, 2013).

\section{The availability of $U G S$}

We now turn to the analysis of how the availability of UGS per inhabitant at the neighbourhood level changed in the period under consideration (see Figure 8.2). In Vienna, the shares of UGS in densely built and populated inner-city districts range from $2 \%$ to $15 \%$ (from the city centre within the Ring to areas between the Ring and the Gürtel). In the fringe districts, UGS shares range from $40 \%$ to $70 \%$. Our analysis of UGS availability builds on the supply standards defined by the City for Green Space Equity. We applied the $3.5 \mathrm{~m}^{2}$ UGS per inhabitant within $250 \mathrm{~m}$ threshold as the availability of UGS proxy. ${ }^{1}$ The spatial analysis shows most of the statistical units are well-served with an adequate amount of green space. A recent study conducted by the City of Vienna found that two-thirds of Vienna's dwellers live a maximum of 250m from the closest publicly accessible UGS (MA22, 2015). Our analysis found that in 2018 about $92 \%$ of the population are adequately served with UGS. Differences might be explained by distinct statistical methods in the aggregation of UGS to the statistical units.

Nevertheless, persistent pockets exist within the city centre and between the Ring and Gürtel that have an inadequate supply of UGS 


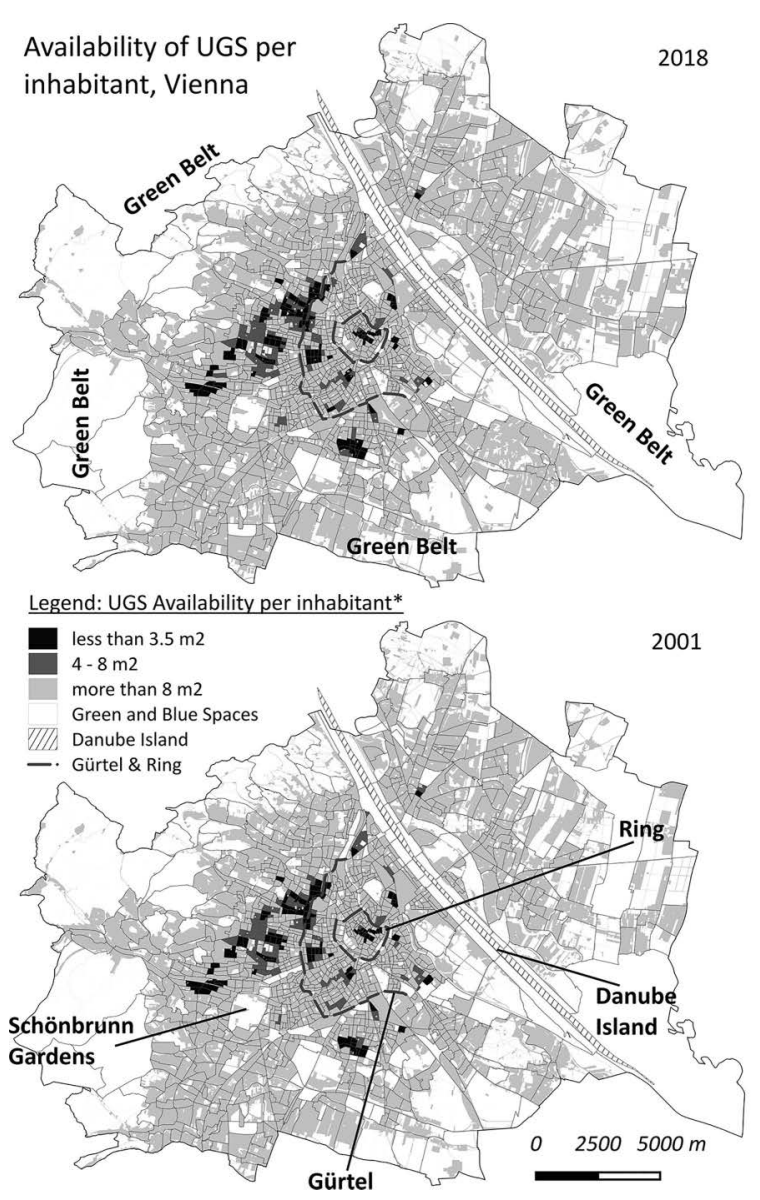

Figure 8.2 Availability of UGS per inhabitant, 2001 and 2018.

Sources: Land-Use Data: Stadt Wien - data.wien.gv.at, 2001 and 2018; Population Data: MA23 - Wirtschaft, Arbeit und Statistik.

(less than $3.5 \mathrm{~m}^{2}$ per inhabitant). Most remarkable, however, is a larger agglomeration of statistical units lacking adequate UGS availability outside of the western Gürtel. These areas are partly marked by high shares of sub-standard apartments and a relative over-representation of low-skilled residents (Hatz et al., 2015). In contrast, the protected areas of the green belt mainly serve wealthier households in the surrounding western districts, especially in the 13th, 18th and 19th districts - characterised by the highest average net income in the city (Statistik Austria, 2019). 
Although disparities exist, our analysis suggests that access to UGS is relatively widespread among the population, especially when considering the steep population growth of recent decades in Vienna. Between 2001 and 2018, the population increased by nearly 340,000, and the population density rose from 236 to 260 inhabitants per ha built-up area. In contrast, areas with less than $3.5 \mathrm{~m}^{2}$ UGS per inhabitant declined by only $1 \%$. That suggests that the City managed the population growth fairly well, which is related to the City's socially inclusive and environmentally friendly urban expansion (see Chapter 4 by Litschauer and Friesenecker in this volume). However, pressures on areas with scarce green spaces intensified, as displayed in Figure 8.2, since population density increased in already densely populated inner-city districts. Rising pressures might also be produced by different patterns of use of green spaces. In this regard, Höglhammer et al. (2019) show that immigrants from non-western countries are underrepresented in their use of the city's Biosphere Park in the green belt since they are not aware of its existence.

\section{Conclusions}

In this chapter, we analysed UGS development over the past 30 years. We employed EJ as an analytical concept that allowed us to identify how distribution and recognition in strategic planning have been addressed, encouraging different forms and qualities of places.

Since the beginning of the 20th century, the city government has promoted a socially and health-oriented UGS provision that fosters equal opportunities for everyone. Whilst other European cities have experienced a gradual shift towards more market-oriented management of UGS, especially in Central and Eastern Europe (Kronenberg et al., 2020), our analysis shows that Vienna's UGS governance was and continues to be characterised by a strong state-based approach. The city maintained its socially and health-oriented policy approach, and it provided more diverse types of UGS to adapt planning ideals/ values to the different and changing needs of the population. Whether the groups targeted by such planning are actually attracted by the quality and design of UGS is not clear and requires further research. The introduction of the principle of Green Space Equity represents a change, emphasising the needs of UGS provision in the vicinity of residential locations. Compared to other 'green' cities, this egalitarian approach to UGS provision is rather a novelty. Amsterdam, for instance, has aimed to ensure access to UGS for all residents by a maximum of ten minutes' walk since 1935 (Anguelovski et al., 2018). Further, Austria's accession to the EU provided new regulations to protect UGS. 
That strengthened the policy approach of the city government, which enhanced the protection of large parts of the green belt for present and future generations, thus making sustainability a crucial principle in UGS planning and management.

Considering UGS distribution, our findings showed that Vienna strived to widen the diffusion of UGS across the city. Whilst the UGS share has remained relatively stable over the last 30-year period, uneven patterns of available UGS $\mathrm{m}^{2}$ per inhabitant have also remained stable. According to our results, although the majority are provided with a decent amount of green space, persistent pockets of underprovision exist. The aim to connect the city via green corridors shifted over time towards a more diverse distribution of green spaces throughout the city. Achievements were constantly challenged by increasing population density, path-dependent urbanisation patterns, and barriers to greening rooted in the institutional setting in inner-city areas. Of course, our measurements of UGS availability are a rough approximation of reality, thus not enabling us to draw any conclusions about the quality of UGS. Furthermore, we need to consider that problems related to the lack of green spaces might be compensated by Vienna's efficient public transport system, which brings residents in a relatively short time to larger green spaces. Finally, effects of climate mitigation might be contained by already existing small-scale UGS, not captured by the land-use data applied in this study.

However, to address necessary climate adaptation strategies and improve quality of life for all people in urban areas, further revitalising of UGS in densely populated urban areas is paramount. To date, the provision of large-scale UGS alone has proved to be insufficient. It remains to be seen whether the advancement of UGS is evolving fast enough, especially in densely built areas, to compensate for negative health impacts due to rising temperatures (especially for the elderly and deprived).

\section{Note}

1 In a GIS program, we calculated a $250 \mathrm{~m}$ catchment radius around landuse-based UGS zoning categories (cemeteries, parks, forests, meadows, vineyards, agrarian fields). Then we apportioned the data to the smallest available spatial unit (ca. 1,360 census tract). We merged the census tracts with information about the UGS share with the census tracts containing information about the total population. Some census tracts are only partly covered by the $250 \mathrm{~m}$ UGS catchment radius. Thus, we normalised the share of UGS by the ratio of the area of the catchment vis-á-vis the area of the census tracts. Finally, we divided the normalised share of UGS by the total population for each census tract. 


\section{References}

Anguelovski, I., Argüelles, L., Baró Porras, F., Cole, H.; J. J.T., GarcíaLamarca, M., 2018. Green Trajectories-Municipal policy trends and strategies for greening in Europe, Canada and United States (1990-2016). [pdf] Available at: https://bit.ly/3cEPo6k [Accessed 01 April 2021].

Bishop, P., Martinez Perez, A., Roggema, R. and Williams, L., eds., 2020. Repurposing the green belt in the 21st century. UCL Press. https://bit.ly/3wlp2hv

Breiling, M. and Ruland, G., 2008. The Vienna green belt: From localised protection to a regional concept. In: Amati, M., ed., 2008. Urban green belts in the twenty-first century. London and New York: Routledge, pp. 167-183.

City of Vienna, 2013. EU-Projekte für Wien-Überblick FörderprogrammRegionale Wettbewerbsfähigkeit und integrative Stadtentwicklung. [pdf] Available at: https://bit.ly/3u851YC [Accessed 02 April 2021].

Dryzek, J.S., ed., 2003. Green states and social movements: Environmentalism in the United States, United Kingdom, Germany, and Norway. Oxford: Oxford University Press.

Gough, I., Meadowcroft, J., Dryzek, J., Gerhards, J., Lengfeld, H., Markandya, A. and Ortiz, R., 2008. JESP symposium: Climate change and social policy. Journal of European Social Policy, 18(4), pp. 325-344.

Hatz, G., Kohlbacher, J. and Reeger, U., 2015. Socio-economic segregation in Vienna: A social-oriented approach to urban planning and housing. In: Tammaru, T., Marcinczak, S., van Ham, M. and Musterd, S., eds., 2015. Socio-economic segregation in European capital cities: East meets west. London: Routledge, pp. 80-109.

Höglhammer, A., Muhar, A. and Stokowski, P., 2019. Access to and use of the Wienerwald Biosphere Reserve by Turkish and Chinese people living in Austria - Implications for planning. Journal on Protected Mountain Areas Research, 11(2), pp. 11-17.

Kabisch, N., Strohbach, M., Haase, D. and Kronenberg, J., 2016. Urban green space availability in European cities. Ecological Indicators, 70, pp. 586-596.

Kronenberg, J., Haase, A., Łaszkiewicz, E., Antal, A. Baravikova, A., Biernacka, M., Dushkova, D. et al., 2020. Environmental justice in the context of urban green space availability, accessibility, and attractiveness in postsocialist cities. Cities, 106, p. 102862.

Loughran, K., 2020. Urban parks and urban problems: An historical perspective on green space development as a cultural fix. Urban Studies, 57(11), pp. 2321-2338.

MA5, 2020. Rechnungsabschluss-Budget der Stadt Wien. [online] Available at: https://bit.ly/3rJDpIX [Accessed 02 April 2021]

MA18, 1984. Stadtentwicklungsplan 1984. [online] Available at: https://bit.ly/ 39BIVai [Accessed 02 April 2021].

MA18, 1994. Stadtentwicklungsplan 1994. [online] Available at: https://bit. ly/31GOq3a [Accessed 02 April 2021].

MA18, 2005. Stadtentwicklungsplan 2005. Short Report. [pdf] Available at: https://bit.ly/3rEk5wE [Accessed 02 April 2021]. 
MA18, 2015. Thematic concept-green and open space. [pdf] Available at: https://bit.ly/31TySt7 [Accessed 02 April 2021].

MA22, 2015. Öffentlich zugängliche Grünflächen-Analyse. [online] Available at: https://bit.ly/3cHO6HC [Accessed 02 April 2021].

Maas, J., Verheij, R.A., Groenewegen, P.P., De Vries, S. and Spreeuwenberg, P., 2006. Green space, urbanity, and health: How strong is the relation? Journal of Epidemiology \& Community Health, 60(7), pp. 587-592.

Mocca, E., Friesenecker, M. and Kazepov, Y., 2020. Greening Vienna. The multi-level interplay of urban environmental policy-making. Sustainability, 12(4), p. 1577.

OekoBusinessWien, 2019. Beste kommunale Daseinsvorsorge, $€ 695$ Mio. Für moderne Öffis und $€ 64$ Mio. Für noch mehr Grünraum im Kampf gegen den Klimawandel. [online] Available at: https://bit.ly/3utNmMz [Accessed 02 April 2021].

Rechnungshof Österreich, 2005. Wirkungsbereich der Bundeshauptstadt Wien-Prüfungsergebnisse: Stadtentwicklung und Stadtplanung. [pdf] Available at: https://bit.ly/3fBcWL6 [Accessed 02 April 2021].

Riederer, B., Verwiebe, R. and Seewann, L., 2019. Changing social stratification in Vienna: Why are migrants declining from the middle of society? Population, Space and Place, 25(2), p. 2215.

Rode, P., \& Schwab, E., 2017. Public green space in Vienna between utopia and political strategy. In: Hristova, S., and Czepczyński, M., eds., 2017. Public space: between reimagination and occupation. London: Routledge, pp. 147-157.

Rutt, R.L. and Gulsrud, N.M., 2016. Green justice in the city: A new agenda for urban green space research in Europe. Urban Forestry \& Urban Greening, 19, pp. 123-127.

Sorensen, A., 2017. New institutionalism and planning theory. In: Gunder, M., Madanipour, A. and Watson, V., eds., 2017. The Routledge handbook of planning theory. London and New York: Routledge, pp. 250-263.

Statistik Austria. 2019. Lohnsteuerpflichtige Einkommen nach Bezirken 2018_Frauen und Männer. [online] Available at: https://bit.ly/2PNPPSW [Accessed 02 April 2021].

Suitner, J., 2020. Vienna's planning history: Periodizing stable phases of regulating urban development, 1820-2020. Planning Perspectives, pp. 1-22.

Walker, G., 2012. Environmental justice: Concepts, evidence and politics. London and New York: Routledge.

ZAMG-Klimaabteilung, 2019. Klimatologische Kenntage in Wien 1955 bis 2019. [online] Available at: https://bit.ly/3dwy4Qb [Accessed 02 April 2021]. 